\title{
Prevalence and Risk Factors for Gestational Diabetes in Aswan, Egypt According to International Association of the Diabetes and Pregnancy Study Groups (IADPSG) Lobna Farag Eltoony ${ }^{1}$, Salwa Ali Ibrahem ${ }^{2}$, Mohammed Zain El-dean Hafez ${ }^{1}$, Omaima Mohamed Ali ${ }^{3}$, Wael Abd Elgwad Elsewify ${ }^{* 3}$ \\ ${ }^{1}$ Department of Internal Medicine, Internal Medicine Department, Faculty of medicine, Assuit University, Egypt \\ ${ }^{2}$ Department of Internal Medicine, Aswan University Hospital, Aswan, Egypt \\ ${ }^{3}$ Department of Internal Medicine, Faculty of Medicine, Aswan University, Aswan, Egypt \\ *Corresponding author: Wael Abd Elgwad Elsewify, Mobile: +201001657295, Email: waelelsewify@ yahoo.com
}

\begin{abstract}
Background: The prevalence of diabetes in Egypt has significantly increased exceeding international rates. Egypt is now ranked ninth highest in the world in terms of the disease according to IDF, 2019.

Objective: Estimation of the prevalence of gestational diabetes mellitus (GDM) in Aswan Governorate in Egypt and determination of the risk factors associated with GDM.

Patients and methods: Our study was a prospective study, which carried out in the Antenatal Clinic in the Obstetrics and Gynecology Department, Aswan University Hospital from July 2016 to July 2017. The pregnant women were collected form Aswan Governorate as part of a Gestational Diabetes care in Upper Egypt project in collaboration with World Diabetes Foundation. Our study included 1000 pregnant woman. All participants were screened for GDM at 24-28 weeks of gestation. Universal screenings for GDM were performed for the participants using oral glucose tolerance test (OGTT) according to International Association of Diabetes and Pregnancy Study Groups (IADPSG) recommendations 2017.

Results: According to IADPSG criteria, $17.5 \%$ of the screened cases had GDM, 16.8\% had fasting blood glucose level $\geq 92 \mathrm{mg} / \mathrm{dL}, 15.5 \%$ had 1 -hour OGTT $\geq 180 \mathrm{mg} / \mathrm{dL}$ and $16.7 \% \mathrm{had} \geq 153 \mathrm{mg} / \mathrm{dL}$. It was found that the age $\geq 25$ years and multiparity were significantly higher in GDM than in Non-GDM. Pregnant women living in rural areas and working women were significantly protected against GDM than those from urban areas. Both family history of diabetes and previous history of GDM represented the major risk factor in our studied group ( $\mathrm{P}<0.001 \&<0.001$ respectively). $40.4 \%$ of studied group exhibited no definite risk factors. There were significant increases in systolic B.P, diastolic B.P in GDM group versus non-GDM ( $p<0.001 \& \mathrm{p}<0.001$ respectively). BMI was significantly higher in GDM than non-GDM ( $\mathrm{p}=0.024)$.
\end{abstract}

Conclusion: GDM was highly prevalent in Aswan Governorate with a rate of $17.5 \%$. The major risk factors of GDM were family history of DM and previous history of GDM, increase in age >25 and multiparity and obesity.

Keywords: Gestational diabetes, OGTT, Prevalence, Risk factors.

\section{INTRODUCTION}

The rate of diabetes in Egypt have significantly increased exceeding international rates. The International Diabetes Federation (IDF) listed Egypt among the world top 10 countries in the number of patients with diabetes. Gestational diabetes mellitus (GDM) is a common pregnancy complication, in which spontaneous hyperglycemia develops during pregnancy. According to the most recent IDF estimates, GDM affects approximately $14 \%$ of pregnancies worldwide, representing approximately 18 million births annually ${ }^{(\mathbf{1})}$.

Risk factors of GDM include overweight/obesity, westernized diet and micronutrient deficiencies, advanced maternal age and family history of insulin resistance and/or diabetes. While GDM usually resolves following delivery, it can have long-lasting health consequences, including increase risk of shortand long-term complications for mother and child ${ }^{(2)}$.

\section{AIM OF THE WORK}

The objectives of this study were the assessment of the prevalence of GDM among pregnant females at 24-28 weeks gestation in Aswan Governorate, which is a big governorate in south of Egypt (1.323.215 million population) $\left(62.726 \mathrm{~km}^{2}\right)$. We used the International Association of the Diabetes and Pregnancy Study Groups (IADPSG) criteria to identify the possible association of GDM with a number of risk factors in a sample of the Egyptian pregnant population to increase awareness about GDM and early detection of it among pregnant women.

\section{PATIENTS AND METHODS}

Our study was a prospective study carried out in the Antenatal Clinic in the Obstetrics and Gynecology Department at Aswan University Hospital during period from July 2016 to July 2017. The pregnant women were collected form Aswan as part of a Gestational Diabetes care in Upper Egypt project in 
collaboration with World Diabetes Foundation (WDF) (13797).

\section{Inclusion}

\section{criteria:}

All non-diabetic pregnant woman attending to Antenatal Care screened for risk factors of gestational diabetes between 24-28 weeks gestational age.

Exclusion criteria: The women with diabetes history before pregnancy or overt diabetes mellitus (DM) ((fasting $\geq 126 \mathrm{mg} / \mathrm{dl}$ or two hours post-prandial $\geq$ $200 \mathrm{mg} / \mathrm{dl}$ ) were excluded from the study. Women known to be hypertensive were also excluded from the study.

A total 1000 pregnant women between 24-28 weeks of gestation attending to Antenatal Care (Obstetric Department) participated in the study. All women were subjected to detailed obstetric history regarding age, parity, obesity, family history of DM, any previous obstetric complications, history of delivery of a baby weighing greater than or equal to 4 $\mathrm{kg}$, family history of diabetes mellitus in a first degree relative, history of unexplained stillbirths and two or more spontaneous miscarriages in addition to full systemic examination .

All women were examined as regards weight, height and body mass index (BMI) was calculated. All participants were screened for GDM at 24-28 weeks of gestation using oral glucose tolerance test (OGTT). They were given $75 \mathrm{gm}$ of glucose anhydrous dissolved in $200 \mathrm{ml}$ of water. Fasting, one hour, two hours blood glucose levels were estimated. Universal screenings for GDM were performed for the participants according to International Association of Diabetes and Pregnancy Study Groups (IADPSG) recommendations.

The diagnosis of GDM was made when any one of the following plasma glucose values were exceeded, if the fasting plasma glucose was $92 \mathrm{mg} / \mathrm{dL}(5.1$ $\mathrm{mmol} / \mathrm{l})$ or greater, 1-hour $180 \mathrm{mg} / \mathrm{dL}(10.0 \mathrm{mmol})$ or greater or when the 2- hour value is $153 \mathrm{mg} / \mathrm{dL}(8.5$ $\mathrm{mmol} / \mathrm{l}$ ) or greater. Values (fasting $\geq 126 \mathrm{mg} / \mathrm{dl}$ or two hours post-prandial $\geq 200 \mathrm{mg} / \mathrm{dl}$ ) indicate overt diabetes mellitus, which was excluded from the study.

Ethical Statement: We confirm that the present study runs in compatibility with international ethical standards and applicable local regulatory guidelines. The study does not have any physical, psychological, social, legal, economic, or any other anticipated risks to study's participants. Participants in the study were informed about objectives, methods, risks and benefits. A written informed consent was obtained from each eligible patients in the study. The study was reviewed and approved by Ethics Committee of Faculty of Medicine, Aswan University.

\section{Statistical Analysis}

An Excel spreadsheet was performed for data entry; validation checks are used on numerical variables and option-based data entry method for categorical variables to minimize potential errors. The analyses were done by SPSS software (Statistical Package for the Social Sciences, version 24, SSPS Inc, Chicago, IL, USA). The normality of the data were assessed using Shapiro-Wilk Test. Numerical data were described as mean \pm SD if normally distributed; or median and interquartile range [IQR] if not normally distributed. Frequency tables with percentages were used for categorical variables. Independent Student ttest and paired t-test were used to compare parametric quantitative variables; while Mann-Whitney tests and Wilcoxon matched pairs test were used to compare non-parametric quantitative variables. Chi-square test or McNemar-Bowker tests were used to analyze categorical variables. P-value $\leq 0.05$ is considered statistically significant.

\section{RESULTS}

According to IADPSG criteria for diagnosis of GDM, 17.5\% of the screened cases had GDM (Figure 1). While according to DIPSI and WHO criteria for diagnosis of GDM, 18.4\% of cases had GDM. After screening by IADPSG, $16.8 \%$ had Fasting blood glucose level ( $\geq 92 \mathrm{mg} / \mathrm{dL}), 15.5 \%$ have 1-hour OGTT $(\geq 180 \mathrm{mg} / \mathrm{dL})$ and $16.7 \%$ had $(\geq 153 \mathrm{mg} / \mathrm{dL})$ (Table 1 , Figure 1).

In current study, it was found that the age $\geq 25$ years and multiparity were significantly higher in GDM than in Non-GDM. Furthermore, pregnant women in rural areas were significantly protected against GDM than those from urban (Table 2).

Table (3) showed that family history of diabetes was the commonest risk factor in the studied group (32.3\%), followed by previous history of GDM (5.9\%). $40.4 \%$ of studied group exhibited no definite risk factor, which enlarge the use of universal screening for GDM rather than selective screening. In the studied group, it was found that $72 \%$ of the studied pregnant women were overweight and obese (Table 3, Figure 2). In our study, the mean value of systolic blood pressure (BP) and diastolic BP was 117.28 $\pm 14.05,74.21 \pm 9.58$ $\& 83.92$ respectively (Figure 3 ).

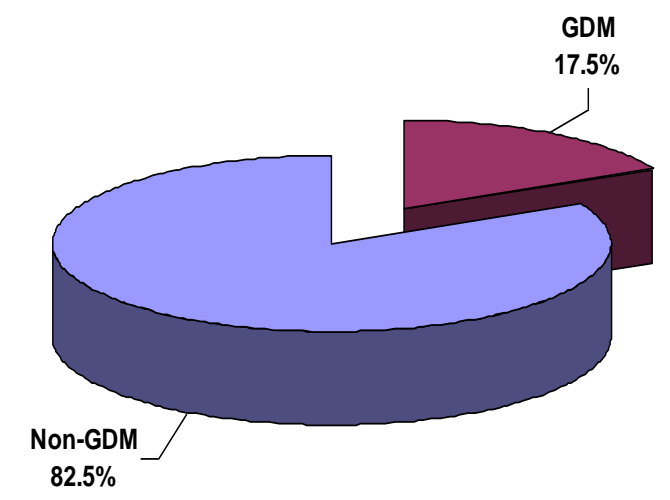




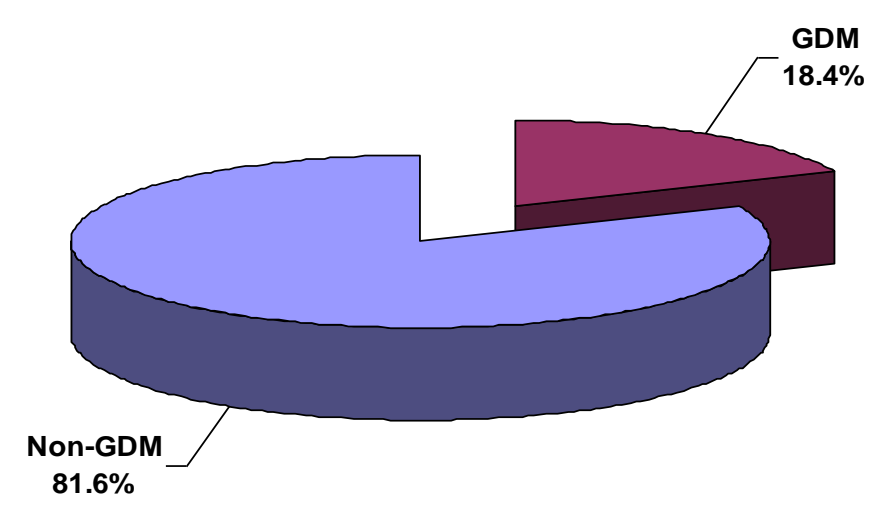

Fig. (1): Diagnosis of GDM in the studied pregnant women according to IADPSG criteria.

Fig. (2): DIPSI and WHO 1999 criteria for diagnosis of GDM.

Table (1): GDM among studied group after screening by IADPSG

\begin{tabular}{|c|c|c|c|c|c|c|c|c|c|}
\hline & \multicolumn{2}{|c|}{$\begin{array}{c}\text { Fasting } \\
(\mathrm{n}=\mathbf{1 0 0 0}) \\
(\geq 92 \mathrm{mg} / \mathrm{dL})\end{array}$} & \multicolumn{2}{|c|}{$\begin{array}{c}\text { 1-hour OGTT } \\
(n=1000) \\
(\geq 180 \mathrm{mg} / \mathrm{dL})\end{array}$} & \multicolumn{2}{|c|}{$\begin{array}{c}\text { 2-hour OGTT } \\
(\mathrm{n}=1000) \\
(\geq 153 \mathrm{mg} / \mathrm{dL})\end{array}$} & \multirow[t]{2}{*}{ P-value ${ }^{1}$} & \multirow[t]{2}{*}{ P-value ${ }^{2}$} & \multirow[t]{2}{*}{ P-value } \\
\hline & No. & $\%$ & No. & $\%$ & No. & $\%$ & & & \\
\hline GDM & 168 & 16.8 & 155 & 15.5 & 167 & 16.7 & \multirow{2}{*}{0.430} & \multirow{2}{*}{0.952} & \multirow{2}{*}{0.465} \\
\hline Non-GDM & 832 & 83.2 & 845 & 84.5 & 833 & 83.3 & & & \\
\hline Mean \pm SD & \multicolumn{2}{|c|}{$94.26 \pm 13.80$} & \multicolumn{2}{|c|}{$161.22 \pm 18.22$} & \multicolumn{2}{|c|}{$159.11 \pm 14.73$} & $0.00^{*}$ & $0.00 *$ & 0.238 \\
\hline
\end{tabular}

1. Fasting GDM versus fasting non-GDM (P-Value $1=0.430) . \quad 2$. First OGTT in GDM versus nonGDM (P-Value $2=0.952)$. $\quad 3$. Second hour OGTT in GDM versus non-GDM (P-Value3 $=0.465)$.

Table (2): Baseline characteristics of the studied pregnant women

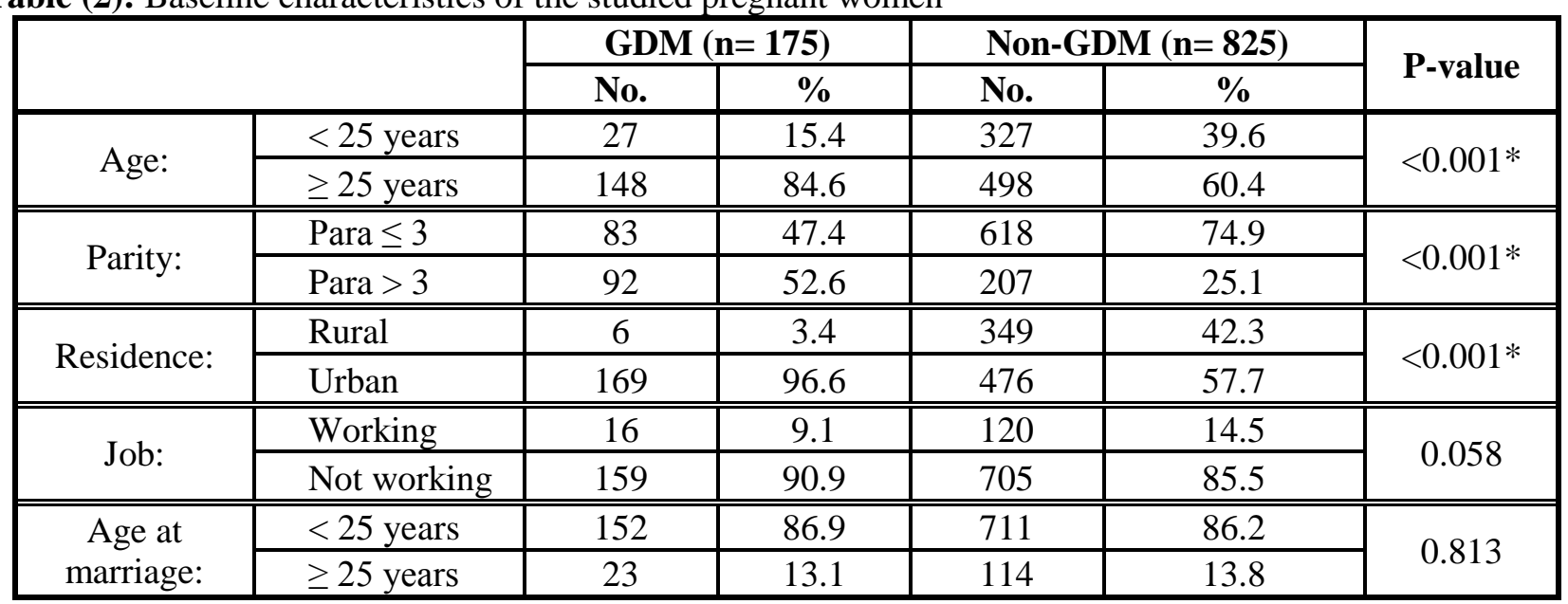

In current study, it was found that the age $\geq 25$ years and parity $>3$ were significantly higher in GDM than in NonGDM. Furthermore, pregnant women in rural area and working women were significantly protected against GDM.

Table (3): Multi variant regression analysis for prediction of risk factor of GDM

\begin{tabular}{|l|c|c|c|c|}
\hline & \multirow{2}{*}{ P-value } & \multirow{2}{*}{ OR } & \multicolumn{2}{|c|}{ 95\% C.I. } \\
\cline { 4 - 5 } & & & Lower & Upper \\
\hline Family history of diabetes & $\mathbf{0 . 0 0 2} *$ & $\mathbf{5 . 4 8 9}$ & 1.209 & 11.082 \\
\hline Previous GDM & $\mathbf{0 . 0 0 4}$ & $\mathbf{4 . 1 0 7}$ & 1.040 & 17.440 \\
\hline PCO & 0.305 & 1.053 & 0.973 & 1.159 \\
\hline History of macrosomic baby & 0.819 & 1.173 & 0.209 & 5.415 \\
\hline Twin pregnancy & 0.351 & 1.025 & 0.961 & 1.793 \\
\hline
\end{tabular}

$\mathrm{P}$-value is considered significant if $<0.05, \quad *=$ significant. 
In our study, It was found that both family history of diabetes and previous history of GDM represented the major risk factors in our studied group ( $\mathrm{P}$-value $<0.002 *,<0.004 *$ respectively).

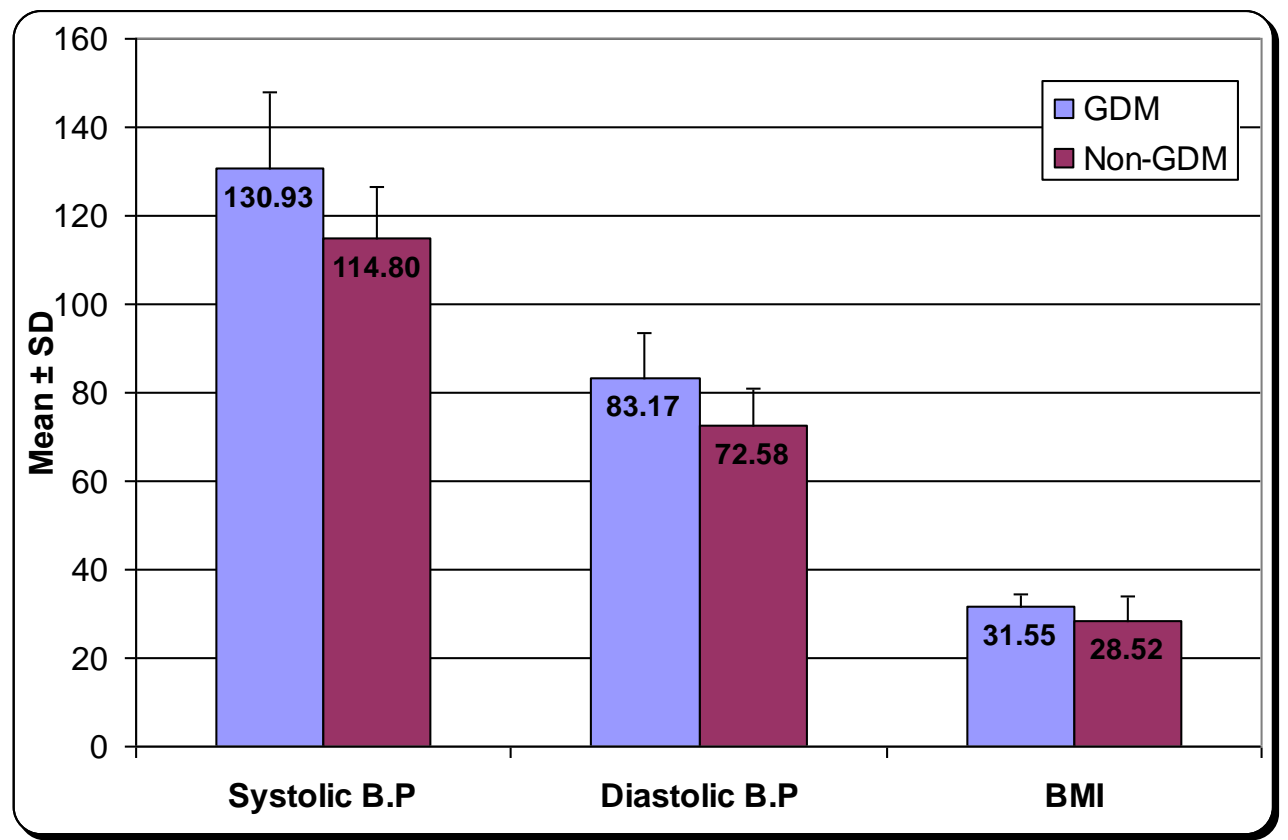

Fig. (3): Vital signs and anthropometric measure of GDM women versus non-GDM There were increase in blood pressure in GDM versus non-GDM but did not reach the level of hypertension.

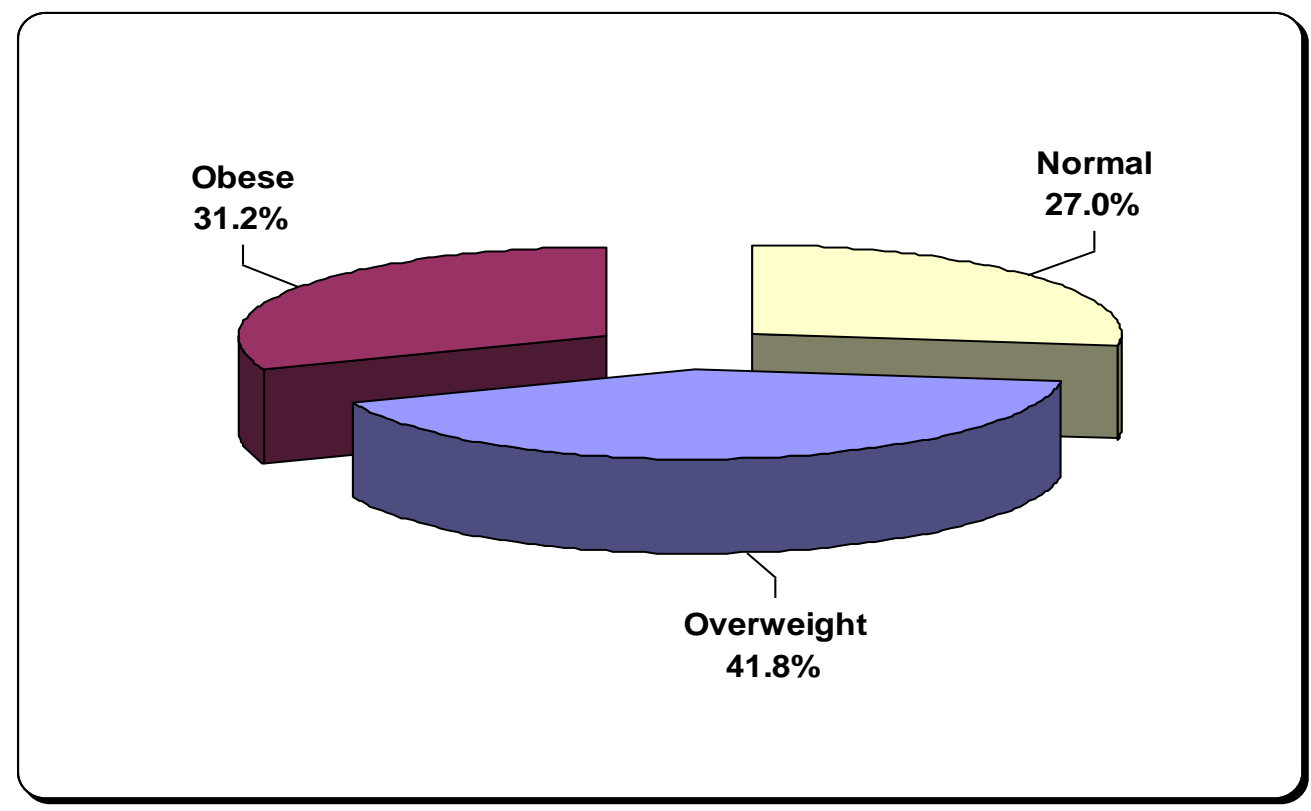

Fig. (4): Body mass index of the studied pregnant women

In the studied group, it was found that $72 \%$ of the studied pregnant women were overweight and obese

\section{DISCUSSION}

Gestational diabetes mellitus (GDM), defined by the World Health Organization (WHO) as carbohydrate intolerance resulting in hyperglycaemia of variable severity with onset or first recognition during pregnancy, is the most common metabolic disorder of pregnancy ${ }^{(3)}$.

The $8^{\text {th }}$ edition of the IDF Diabetes Atlas released in 2017 estimated that the prevalence of diabetes in pregnancy (DIP) to be $2.2 \%$ and GDM $14.0 \%$ with total prevalence of hyperglycemia in pregnancy (HIP) at $16.2 \%{ }^{(3)}$. This increase in the $9^{\text {th }}$ edition may be due to a change in the study criteria scoring since the introduction of the IADPSG and may not reflect an actual increase in HIP prevalence.

Although asymptomatic in its clinical course, GDM is associated with an increased risk of complications related to pregnancy and childbirth ${ }^{(4)}$.

Despite decades of researches and debate, controversy regarding the optimal strategy for screening and diagnosis of GDM has persisted. Guidelines from the majority of countries recommend universal screening ${ }^{(\mathbf{5}, \mathbf{6})}$. Timing of screening focuses on gestational week 24-28 for all women not known to have preexisting diabetes, although one consensus statement advises screening specifically in week $24^{(7)}$. 
Guidelines from two countries advise selective screening in the presence of risk factors only ${ }^{(8)}$.

The current study was a prospective study, carried out in the Antenatal Clinic in the Obstetrics and Gynecology Department, Aswan University Hospital. The pregnant women were collected form Aswan Governorate in south of Egypt. The study was done on a total 1000 pregnant women between 24-28 weeks of gestation to make early diagnosis of GDM and to determine the risk factors associated with GDM.

In our study, $17.5 \%$ of the universal screened pregnant women had GDM versus $82.5 \%$ had not GDM. The main reason for the high prevalence of GDM in this study setting might be the fact that the lower cut-off points for FPG and OGTT were used in the updated diagnostic criteria. This was the first study in south Egypt examining the prevalence of GDM according to our knowledge.

Also, diagnosis of GDM was done by DIPSI criteria $2 \mathrm{hr}$ OGTT $\geq 140 \mathrm{mg} / \mathrm{dl}$ we found that $18.4 \%$ had GDM versus $81.6 \%$ had non-GDM so the study revealed GDM prevalence $17.5 \%$ based on IADPSG criteria versus $18.4 \%$ based on DIPSI criteria. DIPSI criteria is more sensitive and specific than IADPSG criteria. Conserversly, still exist about the sensitivity and effectiveness of DPSI versus commonly used criteria for GDM screening as WHO and IADPSG. This result is in agreement with some studies conducted in Egypt $(8 \%)^{(\mathbf{9})},(8.86 \%){ }^{(\mathbf{1 0})}$ and $(14 \%)$ in Assuit ${ }^{(11)}$. In the neighboring countries of Bahrain, Oman, Qatar ranging from $10.1 \%$ to $24.9 \%{ }^{(12)}$. In addition, in Kuwait, GDM was estimated to be $12.6 \%{ }^{(13)}$, in Saudi Arabia was $15.4 \%{ }^{(\mathbf{1 2})}$, while in UAE was $13.3 \%{ }^{(\mathbf{1 4})}$. In Rwanda was $8.3 \%^{(15)}$, in Tanzania was $5.9 \%^{(16)}$ and in Iran reported $3.41 \%$ prevalence of GDM (16). Furthermore, prevalence reaching $19.19 \%$ in Indian women ${ }^{(17)}$. Comparing our result with other researches done in Egypt, it is found that, as we go to the south of Egypt, the prevalence of GDM increases, El-monofia, El-minia, Assiut and Aswan (8\%, 8.86\%, 14\% \& $17.5 \%$ respectively). This is in agreement with Rönö et al. ${ }^{(18)}$ who showed that the incidence of GDM was high at $16.5 \%$ in finish women. Our results are higher than those among pregnant women in Northwest Ethiopia by Muche et $\boldsymbol{a l}$. ${ }^{(19)}$ as $12.8 \%$ were diagnosed with GDM and higher than that of $13 \%$ by Nair et al. (20) from Kolkata, Bengaluru, while $10.8 \%$ according to Nascimento et al. (21) study among Brazilian women. However, our results were not in agreement with study by Anzaku and Musa ${ }^{(22)}$ done in Nigeria, which reported $8.3 \%$ prevalence of GDM, in Tanzania was $19.5 \%{ }^{(23)}$ and in South Africa $25.8 \%{ }^{(24)}$. This difference may be related to difference in diagnostic criteria used or population studied. This evidence indicates that the prevalence of GDM might also be affected not only by different diagnostic criteria but also by the characteristics of the population. Increased testing for GDM, change in lifestyle, and the rising prevalence of overweight and obesity might have contribution.

In the current study, it was found that the age $\geq$ 25 years and multi-parity were significantly higher in GDM than in Non-GDM. Furthermore, pregnant women in rural areas and working woman were significantly protected against GDM than those from urban areas. This is in agreement with Macaulay et al. (25) who demonstrate that the transition from rural to urban lifestyle with changes in eating habits, western diet with increased consumption of fats, sugars and refined carbohydrates, increased body mass and decreased physical activity increase the chance of obesity and GDM . Furthermore, in agreement with our results, Groof $\boldsymbol{e t}$ al. ${ }^{(13)}$ found that, the prevalence of GDM was increased linearly as maternal age increased. However, the impact of increasing age on the risk of GDM seems to be modified by ethnicity; non-Hispanic whites and Hispanics being more adversely affected compared to other ethnicities.

In our study, It was found that both family history of diabetes and GDM represented the major risk factors for GDM ( $\mathrm{P}<0.001$ and $<0.001$ respectively). This finding is in line with those studies in Egypt of El Sagheer and Hamdi ${ }^{(26)}$ where the frequent occurrence of GDM showed the presence of common risk factors in succeeding pregnancies. Similarly, GDM was four folds higher in women with family history of diabetes. Furthermore, according to study by Groof $\boldsymbol{e t}$ al. ${ }^{(13)}$ women with family history of GDM were more likely to have GDM than those with no family history of GDM. In a retrospective analysis of women diagnosed with GDM in a study by Kumari et al. (6) who demonstrated that family history of diabetes was observed in a significantly higher number of GDM patients $(22.4 \%)$ as compared to control group (10\%) $(\mathrm{P}=0.002)$.

In our study, no definite risk factor was found in $40.4 \%$ of GDM women, which enhance the importance of universal screening.

In addition, in our study, body weight \& BMI significantly increased in GDM versus non-GDM ( $\mathrm{p}=$ $0.004 \& 0.024$ respectively) without significant difference in height as $\mathrm{p}=0.161$. High prevalence of BMI > 30 in our study explained by prevalence of sedentary lifestyle and lack of exercise among the studied group. Increasing maternal body mass index (BMI) is a well-recognized risk factor for the development of gestational diabetes, the two conditions sharing a similar metabolic milieu characterized by insulin resistance, hyperglycaemia, hyperlipidaemia, and a low-grade state of chronic inflammation, which in turn has been documented to influence the availability and transfer of nutrients to the developing fetus. Furthermore, adipose tissue, far from being an inert tissue, has a critical role in innate immune sensing, the production of varying adipocytokines (leptin, TNFa, IL-6) and in antagonists to the effect of insulin ${ }^{(27)}$. 
Similarly, in a study by Prakash et al. ${ }^{(28)}$, GDM mothers weighed a mean of $9.9 \mathrm{~kg}$ more than the controls. Their average body mass index (BMI) was 28.8 when compared to 25 in the controls. In addition, in many studies, it was generally accepted that increase in BMI is associated with an elevated risk of developing GDM ${ }^{\text {(29). }}$.

Our results reveled that, there were significant increases in systolic BP and diastolic BP in GDM group versus non-GDM $(<0.001,<0.001$ respectively) but not reach the level of hypertension. This is in agreement with Khalil et $\boldsymbol{a l} .{ }^{\left({ }^{(9)}\right.}$, Erem et $\boldsymbol{a l} .{ }^{(30)}$ and Leng et al. (31) who revealed that gestational hypertension was significantly higher in the GDM group. This is also supported by results of Muche $\boldsymbol{e t}$ al. ${ }^{(19)}$. Similarly, Groof et al. ${ }^{(13)}$ reported that pregnancyinduced hypertension was found to be more common among mothers affected by GDM (25.9\%) as compared to those who did not report GDM (16.2\%). Also, Oppermann et al. ${ }^{(32)}$ showed an increased incidence of pregnancy hypertensive disorders associated with GDM. In accordance with our results, Nair et al. ${ }^{(20)}$ reported that hypertension and preeclampsia were significantly higher in GDM group as compared to controls.

\section{Limitations of our study:}

1. Single center study (Aswan university Hospital).

2. The data concerning weight gain through pregnancy is lacking.

3. Moreover, pre-pregnancy weight was based on patient's self-reported data.

4. Decrease direction for increase in awareness about impact of life style modification during pregnancy.

5. Evaluation of the income and socioeconomic standard of studied group not done as it had a strong effect on type and frequency of dietary intake and nutritional habits.

6. Lack of data on lifestyle-related factors including diet, physical activity and sleeping patterns. Possibly, some women had undiagnosed diabetes mellitus before pregnancy and have therefore been misclassified as having GDM.

\section{CONCLUSION}

GDM shows high prevalent rate of $17.5 \%$ in Aswan Governorate. The major risk factors of GDM were family history of DM, previous history of GDM, increase in age $>25$, multi-parity and obesity, which were significantly higher with GDM than those with no-GDM were.

\section{RECOMMENDATION}

There are still various controversies regarding the ideal approach for screening gestational diabetes and a clear objective evidence-based global approach, which is simple, easy to follow and validated by corroborative research is crucial because lack of consensus creates major problems in addressing prevalence, complications, efficacy of treatment, and follow up of GDM .

Currently, the recommendations for the screening and management of gestational diabetes obey the principle of precaution rather than that of evidencebased medicine. Measurement of at least the fasting blood glucose following the first antenatal visit, in order to detect women who are already diabetic or likely to develop glucose intolerance: the threshold of $1 \mathrm{~g} / \mathrm{l}$ might be adopted and all women testing positive followed up regularly. With the improvement of the screening for GDM, further research to evaluate the maternal and fetal risks by interventional studies needs to be undertaken to manage this risk factor correctly.

\section{REFERENCES}

1. Knowler W, Drews K, Redman L et al. (2018): Changing Glucose Tolerance during PregnancyImplications for Diagnosis of Gestational Diabetes Mellitus (GDM). https://diabetes.diabetesjournals. org/content/67/Supplement_1/119-OR

2. Natamba B, Namara A, Nyirenda M (2019): Burden, risk factors and maternal and offspring outcomes of gestational diabetes mellitus (GDM) in sub-Saharan Africa (SSA): a systematic review and meta-analysis. BMC Pregnancy and Childbirth, 19 (1): 450-5.

3. American Diabetes Association (2016). Classification and diagnosis of diabetes. Diabetes Care, 39 (1): 13-22.

4. Melchior H, Kurch-Bek D, Mund M (2017). The Prevalence of Gestational Diabetes. Dtsch Arztebl Int., 114: 412-418.

5. Vanderijst J, Debiève F, Doucet F et al. (2012): Screening strategy and diagnostic criteria for gestational diabetes. Proposals of the GGOLFB. Revue medicale de Bruxelles, 33 (2): 97-104.

6. Kumari R, Dalal V, Kachhawa G et al. (2018): Maternal and Perinatal Outcome in Gestational Diabetes Mellitus in a Tertiary Care Hospital in Delhi. Indian J Endocrinol Metab., 22: 116-120.

7. Benhalima K (2012): Screening for pregestational diabetes in pregnancy and screening for gestational diabetes consensus 2012 VDV-VVOG-Domus Medica. Proceedings of the Belgian Royal Academies of Medicine, 2: 24-42.

8. Vambergue A (2010): Expert consensus on gestational diabetes mellitus. Diabetes Metab., 36 (6 Pt 2): 511-16.

9. Khalil N, Fathy W, Mahmoud N (2017): Screening for gestational diabetes among pregnant women attending a rural family health center-Menoufia governorate-Egypt. Journal of Family Medicine and Health Care, 6: 3-6.

10. Ghada M, Lamia H (2018): Prevalence and risk factors for gestational diabetes mellitus according to the Diabetes in Pregnancy Study Group India in comparison to International Association of the Diabetes and Pregnancy Study Groups in El-Minya, Egypt. The Egyptian Journal of Internal Medicine, 30: 131-139.

11.El Toony L, Mohamed W, Abdelreqal A (2019): Screening of type 2 diabetes mellitus after gestational diabetes in Assiut University Hospital. Journal of Current Medical Research and Practice, 4: 338-343.

12. Wahabi H, Fayed A, Alzeidan $R$ et al. (2014): The independent effects of maternal obesity and gestational 
diabetes on the pregnancy outcomes. BMC Endocrine Disorders, 14 (1): 47-52.

13. Groof Z, Garashi G, Husain H et al. (2019): Prevalence, Risk Factors, and Fetomaternal Outcomes of Gestational Diabetes Mellitus in Kuwait: A CrossSectional Study. Journal of Diabetes Research, 2019:7.

14. Agarwal M, Dhatt G, Othman Y (2015): Gestational diabetes mellitus prevalence: Effect of the laboratory analytical variation. Diabetes Research and Clinical Practice, 109 (3): 493-9.

15. Niyibizi J, Safari F, Ahishakiye J et al. (2016): Gestational diabetes mellitus and its associated risk factors in pregnant women at selected health facilities in Kigali City, Rwanda. Journal of Diabetes Mellitus, 6 (04): 269-72.

16.Zhu Y, Zhang C (2016): Prevalence of gestational diabetes and risk of progression to type 2 diabetes: a global perspective. Current Diabetes Reports, 16 (1): 712.

17.Li K, Naik S, Alexander M et al. (2018): Screening and diagnosis of gestational diabetes in India: a systematic review and meta-analysis. Acta Diabetologica, 55 (6): 613-25.

18. Rönö K, Masalin S, Kautiainen H et al. (2019): Impact of maternal income on the risk of gestational diabetes mellitus in primiparous women. Diabetic Medicine, 36 (2): 214-20.

19. Muche A, Olayemi O, Gete Y (2019): Prevalence of gestational diabetes mellitus and associated factors among women attending antenatal care at Gondar town public health facilities, Northwest Ethiopia. BMC Pregnancy Childbirth, 19: 334-38.

20. Nair V, Sandhu G, Biswas M et al. (2016): Evaluation of the incidence and outcome of gestational diabetes mellitus using the current international consensus guidelines for diagnosing hyperglycaemia in pregnancy. Int J Reprod Contracept Obstet Gynecol., 5: 3361-6.

21. Nascimento G, Alves L, Leal Fonseca C et al. (2016): Dietary patterns and gestational diabetes mellitus in a low income pregnant women population in Brazila cohort study. Archivos Latinoamericanos de Nutrition, 66: 301308.

22. Anzaku A, Musa J (2013): Prevalence and associated risk factors for gestational diabetes in Jos, North-central, Nigeria. Archives of Gynecology and Obstetrics, 287: 859-863.
23. Njete H, John B, Mlay P et al. (2018): Prevalence, predictors and challenges of gestational diabetes mellitus screening among pregnant women in northern Tanzania. Tropical Medicine \& International Health, 23 (2): 23642.

24. Adams S, Rheeder P (2017): Screening for gestational diabetes mellitus in a South African population: prevalence, comparison of diagnostic criteria and the role of risk factors. South African Medical Journal, 107 (6): 523-7.

25. Macaulay S, Dunger D, Norris S (2014): Gestational diabetes mellitus in Africa: a systematic review. PLoS One, 9 (6): 97871.

26. El Sagheer G, Hamdi L (2018): Prevalence and risk factors for gestational diabetes mellitus according to the Diabetes in Pregnancy Study Group India in comparison to International Association of the Diabetes and Pregnancy Study Groups in El-Minya, Egypt. The Egyptian Journal of Internal Medicine, 30 (3): 131-9.

27. Martin K, Grivell R, Yelland L et al. (2015): The influence of maternal BMI and gestational diabetes on pregnancy outcome. Diabetes Research and Clinical Practice, 108 (3): 508-13.

28. Prakash G, Das A, Habeebullah S et al. (2017): Maternal and Neonatal Outcome in Mothers with Gestational Diabetes Mellitus. Indian J Endocrinol Metab., 21: 854-858.

29.Savona-Ventura C, Vassallo J, Craus J et al. (2016): Biological and biochemical characteristics of a Mediterranean population with Gestational Diabetes Mellitus. Journal of Perinatal Medicine, 44: 377-382.

30.Erem C, Kuzu U, Deger O et al. (2015): Prevalence of gestational diabetes mellitus and associated risk factors in Turkish women: the Trabzon GDM Study. Archives of Medical Science, 11(4):724-28.

31.Leng J, Shao P, Zhang C et al. (2015): Prevalence of gestational diabetes mellitus and its risk factors in Chinese pregnant women: a prospective populationbased study in Tianjin, China. PloS One, 10 (3): e0121029.

32. Oppermann M, Alessi J, Hirakata V et al. (2018): Risk Factors for Pregnancy Hypertensive Disorders in a Cohort of Women with Pregestational Diabetes. Diabetes, 67 (1): 1450-55. 